\title{
Reflexões Sobre o "Brincar" no Trabalho Terapêutico com Pacientes Oncológicos Adultos
}

Reflections on "Playing" in the Therapeutical Work with Adult Patients with Cancer

Ponderaciones Sobre el "Bromear" en el Trabajo Terapéutico con Pacientes Oncológicos Adultos

Renata Carolina Giuliano, Santa Casa de Misericórdia de São Paulo

Luciana Marcia dos Santos Silva \& Nataly Manhães Orozimbo
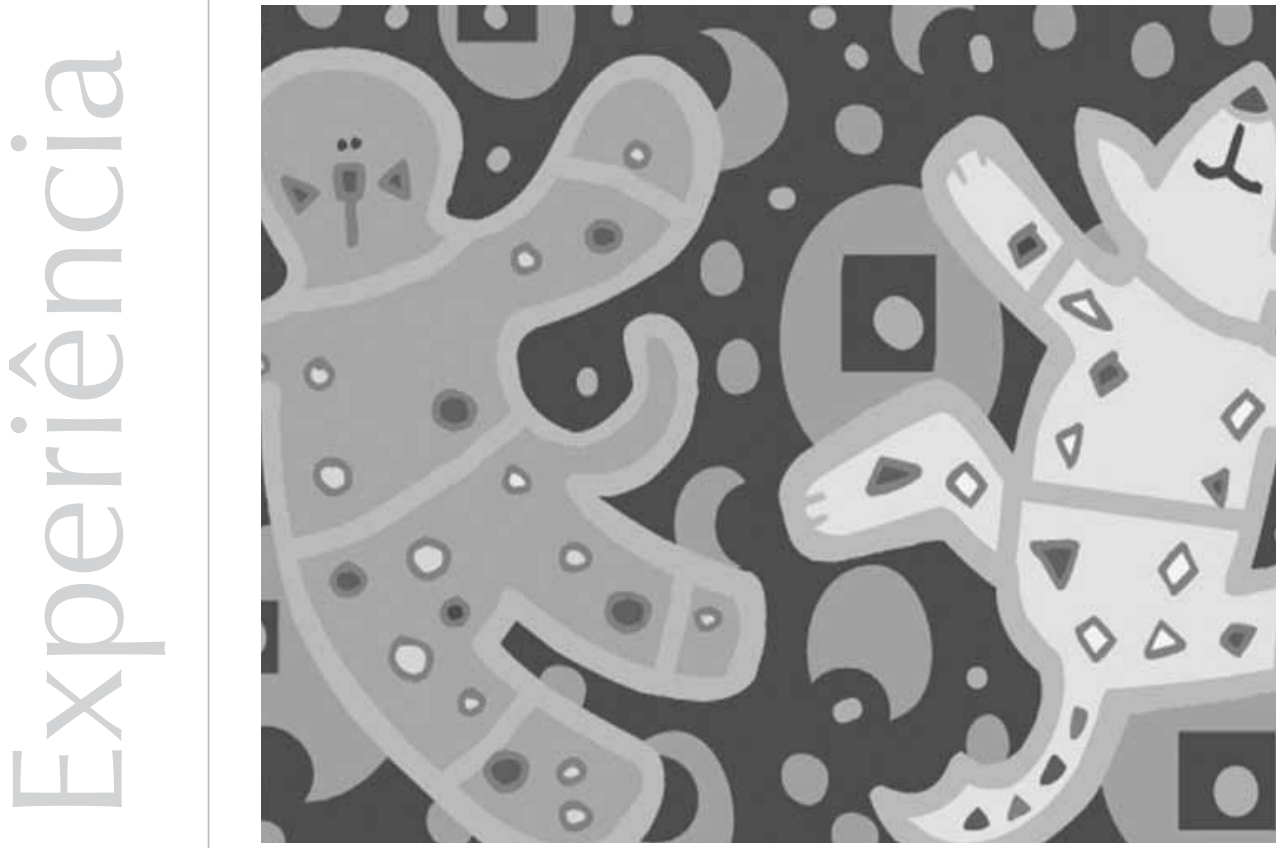
Este artigo é uma versão resumida e atualizada de monografia escrita em

2006, orientada pela professora Maria Elisa de Abreu Pessoa

Labaki, a quem agradecemos pelo apoio e disponibilidade. Para a elaboração deste artigo, contamos com o auxílio da professora Ana Lúcia Gatti, à qual dedicamos este trabalho e agradecemos especialmente pela contribuição, incentivo e amizade.

Resumo: O presente trabalho tem como objetivo refletir sobre o brincar no trabalho terapêutico com pacientes oncológicos adultos, a partir do relato da experiência clínica vivenciada no estágio realizado por uma das autoras. Um breve levantamento bibliográfico foi realizado, visando a compreender a atuação do psicólogo no hospital, seus alcances e limites, a relação com a equipe multiprofissional e o uso de técnicas lúdicas. Dentre as atividades realizadas, destacamos um projeto lúdico que busca, por meio do uso de histórias e de brinquedos, permitir aos pacientes um resgate da sua individualidade, descontextualizando momentaneamente a doença. A reflexão também considerou o adoecer e o câncer assim como o processo de hospitalização e suas conseqüências na vida do paciente. Concluímos que o brincar é uma técnica que contribui para o enfrentamento da doença em pacientes adultos, possibilitando que este ressignifique o seu adoecer e viva esse momento de maneira menos sofrida. Dessa forma, acreditamos que o psicólogo, atuando em projetos psicossociais como o citado, pode atingir seu objetivo de minimizar o sofrimento do paciente.

Palavras-chave: Brincar. Câncer. Psicólogo. Ressignificação.

Abstract: The objective of this paper is to reflect on the utilization of playing in the therapeutical work with adult patients who have cancer, having, as a start, the clinic experience of one of the authors as a trainee. A short research was made in order to comprehend the function of the psychologist inside the hospital, his competences and limits, the multiprofessional relationship and the use of playing techniques. Among the activities, it is the ludic project which tries, by the usage of stories and toys, to allow the patients to gain their individuality back, taking them momentarily out of the disease. The reflection also considered sickness and cancer as well as the process of hospitalization and its consequences to the patient's life. We concluded that playing is a technique that contributes for adult patients to face the disease, helping them to re-signify sickness and to live this moment in a painless manner. In this way we believe that the psychologist can reach the objective of minimizing patients suffering by actuating in projects like the one we mentioned here.

Keywords: Playing. Cancer. Psychologist. Re-signification.

Resumen: El presente trabajo tiene como objetivo reflexionar sobre el bromear en el trabajo terapéutico con pacientes oncológicos adultos, desde el relato de la experiencia clínica vivida en el cursillo realizado por una de las autoras. Un breve levantamiento bibliográfico fue realizado, pretendiendo comprender la actuación del psicólogo en el hospital, sus alcances y límites, la relación con el equipo multiprofesional y el uso de técnicas lúdicas. Entre las actividades realizadas, destacamos un proyecto lúdico que busca, por medio del uso de historias y de juguetes, permitir a los pacientes un rescate de su individualidad, descontextualizando momentáneamente la enfermedad. La ponderación también consideró el enfermarse y el cáncer así como el proceso de hospitalización y sus consecuencias en la vida del paciente. Concluimos que el bromear es una técnica que aporta para el enfrentamiento de la enfermedad en pacientes adultos, posibilitando que éste de nuevo significado a su enfermarse y viva ese momento de manera menos sufrida. De esa forma, creemos que el psicólogo, actuando en proyectos psicosociales como el citado, puede alcanzar su objetivo de minimizar el sufrimiento del paciente.

Palabras clave: Bromear. Cáncer. Psicólogo. Resignificación.

Dentro de instituições hospitalares, o psicólogo lida com imensa gama de sentimentos e situações, além de deparar-se muitas vezes com barreiras para a realização de um trabalho terapêutico, tendo que buscar novas técnicas, adaptando seu conhecimento para melhor atender as necessidades desse contexto.

Frente a essa realidade, este trabalho tem como objetivo apresentar uma técnica lúdica realizada em uma instituição hospitalar especializada no diagnóstico e no tratamento de câncer e refletir sobre a contribuição do brincar na reorganização psíquica de pacientes adultos em tratamento oncológico, baseado no relato de experiência clínica vivenciada por uma das autoras, dando ênfase a uma das atividades desenvolvidas pelo setor de Psicologia.

No sentido de compreendermos esse vasto e surpreendente campo de trabalho da Psicologia, que vem se expandindo e no qual se encontram tantas possibilidades de atuação, buscamos conhecer o trabalho do psicólogo no hospital e algumas circunstâncias com as quais pode se deparar. 


\section{A hospitalização, a morte e o papel do psicólogo no hospital}

Adoecer, na sociedade, é deixar de produzir, e, portanto, de ser; é indigno, logo, esse fato deve ser ocultado e excluído, até porque dificulta que outros, familiares e amigos, também produzam. O hospital age recuperando, quando possível, e devolvendo, com ou sem culpa, o doente à condição de saúde que possuía antes do adoecimento (Pitta, 1994). Em nossa experiência no hospital, percebemos que o adoecer tem um aspecto solitário para o paciente, pois, apesar de haver profissionais e familiares ao redor desse indivíduo, esse momento e os sentimentos despertados são vivenciados individualmente. O psicólogo e os demais que o cercam podem imaginar o que se passa e, a partir disso, atuar, mas, apesar da empatia, não é possível avaliar a real magnitude do significado daquele momento para o paciente. Talvez a equipe e a família, quando tentam amenizar a situação de adoecimento para o paciente, não o façam somente pelo doente, mas por eles mesmos, para atenuar o sentimento de impotência e a angústia que a patologia lhes gera.

É importante destacar que as informações sobre a doença e o tratamento afetam diretamente o modo como o paciente lida com a doença, pois podem desmistificar as fantasias que surgem e assim permitir que ele decida qual o seu papel diante da doença, ao se sentir responsável pelo tratamento e se tornar participante ativo do seu processo de tratamento.

O psicólogo em seu trabalho no hospital pode também auxiliar a equipe de saúde no que diz respeito às suas questões psicológicas, pois o contato com o doente, o sofrimento, as dores constantes e a finitude muitas vezes provocam um movimento de distanciamento para não entrar em contato com sua própria finitude.
De acordo com Pitta, os pacientes e os familiares também alimentam sentimentos complicados em relação ao hospital e à equipe, que são expressos, de modo geral, mais diretamente às enfermeiras. Os pacientes e parentes demonstram estima, gratidão, benignidade, respeito, forte crença de que o hospital funciona e preocupação para com as enfermeiras em seu difícil trabalho. Mas os pacientes freqüentemente se ressentem de sua dependência, aceitam de má vontade a disciplina imposta pelo tratamento e pela rotina hospitalar, são exigentes e possessivos. Os parentes podem ser igualmente exigentes e críticos, principalmente porque sentem que a hospitalização implica inadequações neles mesmos.

A reação de um paciente frente à terminalidade depende das características da personalidade de cada um e pode se encaixar nas reações típicas, descritas por Kübler-Ross e citadas por Leão (1994), de negação, barganha, raiva, depressão e aceitação. Essas reações podem aparecer em momentos diversos, e é comum que sejam dirigidas à enfermagem, pela proximidade física de seus cuidados. O psicólogo precisa ajudar na compreensão desses sentimentos, corrigindo as distorções existentes. Ouvir é o melhor instrumento para alcançar os objetivos terapêuticos reais e possíveis para cada paciente, pois oferece a oportunidade de particularização e de fazer uso da técnica como forma de atendimento humanizador.

A contribuição da Psicologia em determinadas manifestações de somatização é cada vez mais aceita pela equipe médica, pois a influência de questões emocionais no quadro clínico do paciente e a intervenção psicológica nesse processo fazem da Psicologia uma força no diagnóstico e na compreensão da patologia, para a qual a Medicina não tem explicação absoluta (Angerami-Camon, 2003). 
O psicólogo, como profissional da saúde, deve analisar e escutar com calma o que é dito e os silêncios. É preciso compreender e saber decifrar também as condutas e expressões, palavras e gestos (Campos, 1995).
Consideramos que não se deve ver a doença somente como uma produção do doente, estigmatizando-o; não devemos ser extremistas, falando da doença como se sua existência fosse culpa do doente, pois é um processo multifatorial. Além do aspecto psíquico, emocional, há também o ambiental e o hereditário e tudo o que esses fatores abrangem.

O profissional da saúde deveria apreender o doente como um ser-no-mundo, e a compreensão clínica da doença como resultado da relação entre o doente e o mundo. Nesse sentido, perceber como o doente se expressa é importante, e o profissional de saúde poderia se nortear pelo doente, com uma postura de escuta, procurando apreender os fatores psicológicos, sociais ou somáticos que decidem o seu malestar (Barbosa \& Francisco, 2007; Campos, 1995; Figueiredo, 2004).

Nesse contexto, podemos pensar que o aspecto psicólogo também surge na equipe como um facilitador na percepção do paciente como um todo, ajudando a equipe a estender seu olhar para além da doença. O doente tem necessidade de ser escutado e acolhido, e, quando vai solicitar subsídio e internação, tem vontade de melhorar a sua saúde. O psicólogo, como profissional da saúde, deve analisar e escutar com calma o que é dito e os silêncios. É preciso compreender e saber decifrar também as condutas e expressões, palavras e gestos (Campos, 1995).

Romano (2001) afirma que a abordagem do trabalho terapêutico na doença crônica deve ser baseada no modelo biopsicossocial, com a integração da equipe multiprofissional. $\mathrm{O}$ tratamento deverá buscar a minimização dos impactos da doença no paciente e a prevenção de crises emocionais, o que será possível pelo controle das tensões e pela participação do paciente no tratamento proposto, buscando, mesmo em uma situação tão adversa, proporcionar mais qualidade de vida a esse paciente a partir de suas expectativas pessoais quanto à saúde física e mental, às atividades da vida diária e às atividades sociais de lazer, às percepções gerais de bem-estar e à satisfação sobre esses aspectos, e verificar se essas expectativas foram ou não alcançadas.

Consideramos importante destacar o quanto dificulta a inserção do psicólogo na realidade hospitalar o fato de sua formação profissional não abordar algumas características próprias dessa atuação, que dariam uma sedimentação teórico-prática mais condizente com a realidade com a qual o profissional se depara, preparando-o para lidar com as dificuldades inerentes ao âmbito hospitalar.

No hospital, não há um setting terapêutico tão definido e preciso. Muitas vezes, o atendimento é interrompido pela equipe, e é preciso levar em conta certas variáveis. A opção do paciente de receber a intervenção psicológica ou de recusá-la deverá ser respeitada (Angerami-Camon, 2003). Do nosso ponto de vista, sabendo-se que a escolha delimita processos invasivos e que existe passividade na realidade hospitalar, a própria recusa pela intervenção psicológica pode ser considerada psicoterápica, pois o dizer não à intervenção psicológica nesse momento poderá ser o recurso possível desse paciente para resgatar sua individualidade e individuação, que podem estar muito enfraquecidas frente à realidade de internação. Sendo assim, é necessário que o psicólogo consiga perceber, no contato com o paciente, as expressões verbais e não verbais de seu comportamento, de forma a respeitar essa recusa e a não se tornar parte de mais um procedimento invasivo na hospitalização.

\section{O adoecer, o corpo e o câncer: relações psique/soma}

O adoecer é um momento crítico, atípico, para o ser humano, para o qual ele não está 
preparado, quando ocorrem transformações físicas e psíquicas, algumas temporárias, outras definitivas, que mudam sua vida, fazendo-o deparar-se com novas situações que muitas vezes ficam além de seu controle e despertam sentimentos como medo, angústia e ansiedade.

Segundo Souza (2003), atualmente, o homem percebe seu corpo de forma cada vez mais fragmentada e segmentada segundo critérios estéticos, fazendo com que o ser-no-mundo perceba seu corpo apenas pelo que é visível ou pelo seu mau funcionamento. Nesse sentido, a doença seria um modo de o homem comunicar-se com o mundo, expressando sentimentos, conflitos e vivências.

Parestello (1984 como citado por Chiattone, 1992) percebe na doença uma maneira de o homem expressar-se em situações críticas, havendo a necessidade de se buscar uma compreensão da doença, e não uma explicação para ela, no próprio homem. É importante considerar que o ser humano adoece como uma totalidade, sendo que, dessa forma, o câncer tem um significado dentro da história pessoal do paciente.

A doença expressa a maneira como o ser se coloca no mundo. O que o câncer muda na vida da pessoa influenciará diretamente a cura ou a recidiva; dessa maneira, compreendendo essa forma de comunicação e expressão via câncer, o processo de adoecimento pode ser interrompido.

De acordo com Stephan (2002, p. 216), “o problema do câncer não é a doença, é o diagnóstico". O câncer, assim como qualquer doença grave, traz, com seu diagnóstico, o medo da perda de controle sobre a própria vida, o medo do desconhecido, do futuro e das mudanças no corpo, fazendo com que a pessoa interrompa seus planos, permanecendo estagnada, vivendo somente a doença. A ressignificação de sua vida dependerá da história pregressa do paciente e da maneira com que a família, os amigos e também a equipe de saúde irão lidar com a situação, podendo esses fatores contribuir para um bom prognóstico da doença.

A morte, ao longo da História, teve diversas conotações, que variavam de acordo com fatores como cultura, ideologia, processos históricos, etc. A essência da morte é a perda, sentida pelo homem, do significado da vida que lhe é tirado com a morte (Leão, 1994). Dessa forma, uma ressignificação da morte poderá proporcionar qualidade de vida e até de morte para o paciente, que poderá dar sentido a diferentes aspectos de sua existência e finalizar projetos inacabados.

O tratamento do paciente como um ser total e subjetivo, e não apenas como um doente, traz informações que contribuem com o tratamento e com a diminuição do sofrimento, podendo também aumentar as possibilidades de cura.

Após esse apanhado teórico, caracterizaremos, a seguir, a experiência do estágio realizado.

\section{Relato de experiência clínica}

A instituição onde foi realizada a prática clínica era um hospital oncológico que atendia pacientes na maior parte mulheres com câncer de mama e ginecológico, do Sistema Único de Saúde (SUS) (em sua maioria), de convênios e particulares. Além de oferecer atendimento em várias especialidades médicas, o hospital oferecia também serviços de apoio, sendo que dentre eles destacamos o serviço de Psicologia.

O setor de Psicologia oferecia suporte psicoterápico ao paciente, à sua família e aos demais funcionários do hospital, atendendo os casos encaminhados pela equipe multidisciplinar (médicos, equipe de enfermagem, nutricionistas, assistentes sociais, 
fisioterapeutas, fonoaudiólogas), aqueles que o procuravam espontaneamente ou os casos de pacientes que eram abordados pela própria equipe de Psicologia, nos setores de quimioterapia, radioterapia e enfermaria.

O setor de Psicologia era composto por uma psicóloga e duas estagiárias, todas responsáveis pelas seguintes modalidades de atendimento:

1) Psicoterapia breve em âmbitos ambulatorial, quimioterápico, radioterápico, enfermaria e UTI;

2) Grupo de apoio: atendimento psicoterápico em grupo aberto de mulheres;

3) Voluntariado: dois projetos distintos, coordenados pelo setor de Psicologia: o carrinho de lanche e o carrinho com materiais de recreação;

4) Projeto de entretenimento: trabalho com os pacientes, realizado por uma equipe de funcionários e voluntários que se vestem de palhaços;

5) Grupo pré-operatório: envolve profissionais dos setores de nutrição, serviço social, Psicologia e enfermagem;

6) Projeto lúdico: atividade desenvolvida nas enfermarias com o auxílio de material lúdico, que visa a possibilitar os processos de projeção de conteúdos internos ligados ou não ao momento de internação, sendo esse o projeto destacado neste trabalho.

\section{O projeto lúdico}

A utilização desse projeto no presente estudo foi escolhida por representar uma possibilidade de trabalho da Psicologia que não é encontrada em descrições da literatura no acompanhamento de pacientes adultos em tratamento de câncer.

Era um trabalho de cunho psicossocial desenvolvido nas enfermarias com pacientes em tratamento pós-operatório, controle ou cuidados paliativos. Visava a possibilitar o resgate da individualidade de cada paciente, descontextualizando momentaneamente o estado de doença, com o objetivo de devolver sua subjetividade, sua história de vida e seu lugar na família. No contexto social, trabalhava os aspectos subjetivos que foram "abafados" em função da doença e de seu papel de doente, passivo sobre o leito.

As atividades ocorriam de duas a três vezes por semana (não havendo dias específicos), que variavam de acordo com a rotina diária do setor de Psicologia, com maior freqüência no período da tarde, após o horário de visita, com duração média de quarenta minutos. $\mathrm{Na}$ maioria das vezes, as atividades não eram realizadas pela manhã, pois esse era o período em que era realizada a maior parte dos procedimentos médicos e de higiene.

O material utilizado era composto por livros infanto-juvenis, alguns com ilustrações e outros com texto, que envolvem problemáticas de expressão de sentimentos, diferenças individuais, importância da comunicação e reflexão, formas de se compreender uma mesma situação, entre outros, e bichos de pelúcia, utilizados como personagens de histórias a serem criadas pelos pacientes, a partir de uma proposta da equipe de Psicologia, promovendo uma reflexão com os pacientes sobre suas produções. O projeto dava ênfase às questões cotidianas, aos temas existenciais e à expressão livre de sentimentos, focalizando o período atual e futuro, a fim de melhorar o enfrentamento e a qualidade de vida do paciente.

A atividade era proposta aos pacientes como forma de distração, da qual também podiam participar acompanhantes (familiares com qualquer grau de parentesco e/ou amigos) e membros da equipe de saúde, como enfermeiros, auxiliares e técnicos de enfermagem e fisioterapeutas, entre outros, que estivessem disponíveis no momento da 
atividade. Não havia papéis definidos para cada membro; participar do grupo tornava-os iguais, com o objetivo comum de distração e descontextualização do momento de internação. Qualquer participante podia sair da atividade a qualquer momento. Era deixado claro que não se esperava nenhum tipo de resposta certa ou errada para o momento de discussão que era proposto.

Ao final de cada atividade, era pedido um feedback aos pacientes, que relacionavam a atividade com o momento de enfrentamento da doença, os aspectos da internação, as expectativas, a hospitalização, as saudades de casa e os familiares. Percebia-se que a atividade possibilitava aos pacientes uma reflexão sobre sua vida, facilitava a comunicação entre os pacientes e a destes com a equipe de saúde, pois, após as atividades, os pacientes se mostravam mais receptivos, dado que a participação de membros da equipe de saúde na atividade reforçava o sentimento de confiança dos pacientes para com aqueles.

Nas atividades com livros apenas ilustrados, os pacientes descreviam o que viam e o que pensavam estar acontecendo com a personagem, qual o seu objetivo, sentimentos, sensações, dificuldades, projetando assim seus conteúdos internos na história apresentada. A partir daí, iniciava-se a discussão sobre o que foi observado e as diferentes visões e opiniões sobre a história.

Era comum que os pacientes associassem, no momento em que eram discutidas suas percepções, os comportamentos dos personagens com seus próprios comportamentos ou com os das pessoas que os rodeavam, desde membros da equipe até acompanhantes e outras pessoas da família.

Em outra atividade, bichos de pelúcia e outros objetos serviam como ponto de partida para a imaginação de histórias. Ao escolher um dos objetos de dentro de uma sacola, o paciente iniciava uma história, à qual outro paciente dava prosseguimento depois de retirar um novo objeto. Os mais variados assuntos foram centrais em seus discursos. Surgiram conteúdos como afastamento do lar, período de adoecimento ou isolamento, atividades prazerosas, companheirismo, divisão de atividades, ajuda e sentimentos de tristeza, medo, ansiedade e atitudes de passividade e até mesmo de confiança diante do enredo.

O setor de Psicologia, com essa atividade, objetivava proporcionar uma reflexão sobre as diferenças individuais em relação a cada produção construída a partir de objetos aleatórios.

O que nos chamou a atenção no projeto foi sua singularidade no uso dos recursos internos dos pacientes como forma de utilizar o momento de internação para refletir sobre outras questões que estavam presentes em suas vidas, mas que, por vezes, ficavam "abafadas" pela situação emergente de doença.

Não abordaremos, aqui, hipóteses para os significados das respostas, pois nosso objetivo é apresentar uma amostra de como uma atividade que envolve o brincar gera grande diversidade de respostas e oferece uma enorme gama de possibilidades ao profissional de Psicologia.

\section{O brincar}

Assim como Rodulfo (1990), seguindo a proposta de Winnicott, para nós, o brincar está além do brinquedo, pois, enquanto o brinquedo remete ao produto de certa atividade, o brincar tem o caráter de prática significante, uma produção com funções diferentes no decorrer do processo de estruturação subjetiva do indivíduo. 
O brincar está intimamente relacionado com a criança, sendo na infância "o meio pelo qual a criança vai organizando suas experiências, descobrindo e recriando seus sentimentos e pensamentos a respeito do mundo, das coisas e das pessoas com as quais convive" (Ferraz \& Fusari, 1999, p.85).

Freud (1976) afirma que, quando as pessoas crescem e param de brincar, parece que renunciaram a um prazer que tinham. $\mathrm{Na}$ vida adulta, o brincar é apenas deixado de lado, por ser considerado algo de uso exclusivo das crianças. Os adultos, na maioria das vezes, não querem expor seus desejos mais ocultos, desejos esses que eram expressos sem embaraço na infância. Sendo assim, o brincar vai cedendo espaço para a utilização de outros recursos, como a fantasia, para a elaboração da realidade, pois esta não é pública aos olhos do outro, mas está contida dentro do psiquismo do indivíduo.

Winnicott (1971) afirma que brincar é universal e próprio da saúde, um meio de relacionar-se e comunicar-se com o outro e assim conduzir a relacionamentos grupais.

Quando brinca, a criança pode ressignificar sua realidade através dos novos sentidos adquiridos no momento lúdico (Pedroza, 2005; Simões, 2006).

Os pacientes projetam aspectos internos muito significativos no ato de brincar, trazendo à tona conteúdos simbólicos pertinentes à situação pessoal na interação com o corpo e com o meio. Brincar auxilia o sujeito a entrar em contato com seu mundo interior (Vasconcellos \& Giglio, 2007) além de "transformar" o mundo externo, tornando-o, como em uma mágica, mais próximo das fantasias; do ponto de vista da realidade da doença e da dor, a possibilidade de tornar a realidade mais tolerável pode ser vital.
Segundo Winnicott (1971), é no brincar que o paciente manifesta sua criatividade, criatividade essa relacionada com a maneira como o indivíduo se apropria da realidade externa, o colorido de toda sua atitude em relação a essa realidade.

Independentemente das intervenções e das interpretações por parte do terapeuta, o brincar, por suas peculiaridades, cura a criança e o homem. Tal atividade, por si própria, possibilita a transformação e a cura. Ainda que o brincar seja aparentemente algo só da infância, ele proporciona os subsídios do que é essencial para o ser humano.

No trabalho terapêutico com adultos hospitalizados, talvez o projeto descrito seja pioneiro, pois, durante nossos estudos para a realização desse trabalho, não encontramos nenhum projeto que faça uso do brincar como atividade psicossocial com pacientes adultos. Mesmo assim, tendo em vista os conteúdos citados, acreditamos que o brincar, assim como no trabalho realizado com crianças, pode contribuir para o enfrentamento da doença e da situação de hospitalização.

\section{Discussão}

Segundo Santos (2003), adoecer representa um despertar do sujeito para questões que ele sempre quis evitar: sua finitude e sua impotência diante da morte, sendo esse despertar sempre acompanhado de muita angústia, pois o homem da atualidade não está preparado para morrer, que é sentido pelo ser humano como fracasso, é deixar para trás tudo que não se viveu. Ficar doente é ficar mais próximo desse fracasso, é um atestado que fica lembrando a todo o momento que se está perdendo.

O brincar permite que o paciente hospitalizado expresse esse momento de sofrimento, dor, angústia, medos, fantasias e expectativas experienciando esses sentimentos de outra forma, podendo, assim, elaborá-los. 
O indivíduo carece de articular sobre a sua doença e não somente se distrair, pois necessita compreender e expressar suas angústias, seus receios, falando diretamente sobre a história de sua doença. No brincar, ao participar e expor o que vê e sente com as figuras, projetando seus conteúdos internos nos personagens e objetos, o paciente pode repensar seu adoecimento e todos os sentimentos envolvidos nesse momento de sua vida. Essa atividade também se mostra facilitadora da percepção de si mesmo como participante do tratamento e do processo de internação.

Winnicott (1971) afirma que o brincar é um meio de relacionar-se e comunicar-se com o outro, o que, segundo Cunha (1994), permite o contato com o estímulo e a crítica do outro, conduzindo assim a relacionamentos grupais. No projeto realizado no hospital, pudemos perceber que brincar em grupo permite que haja uma troca de experiências entre os pacientes, e essa escuta da experiência do outro pode possibilitar uma reflexão sobre sua própria experiência e o momento que se está passando, o que contribui para a diminuição do sentimento de abandono e isolamento. Após a realização da atividade, foi observado que indivíduos que não interagiam com os demais pacientes do quarto passaram a se comunicar, ofereciam atenção e suporte aos outros.

De acordo com Mrech (1998), o brincar, quando usado em um processo terapêutico, além de mostrar a maneira como a criança foi percebida e avaliada pelos outros, possibilita que a criança supere situações traumáticas por meio da simbolização, fala e representação, podendo elaborar melhor esses conteúdos conflitivos.

Podemos pensar que o brincar com pacientes adultos também possibilita a elaboração de conteúdos conflitivos gerados pela doença, permitindo uma reestruturação desses conteúdos.

Quando existe a representação de determinada circunstância, especialmente se houver verbalização, a imaginação é desafiada pela busca de soluções para os problemas criados na vivência dessa situação. Brincar, imaginar, simbolizar são, portanto, caminhos que a linguagem permite abrir em direção à diminuição de conflitos e angústias (Cunha, 1994).

De acordo com Leão (1994), o psicólogo precisa ajudar na compreensão dos sentimentos envolvidos no adoecer, corrigindo as distorções existentes, sendo que ouvir é o melhor instrumento para alcançar os objetivos terapêuticos reais e possíveis para cada paciente. É ele que oferece a oportunidade de particularização e de fazer uso da técnica como forma de atendimento humanizador.

Como cada pessoa tem uma história própria, experienciará a internação também de uma forma singular. Desse modo, o psicólogo deverá perceber esses aspectos particulares, para amparar e assistir o paciente, manejando a subjetividade a partir do que for constatado (Campos, 1995).

Segundo Campos e Angerami-Camon, no atendimento hospitalar, pode ocorrer uma despersonalização total do paciente, uma vez que o doente é desprovido de seus aspectos existenciais para se tornar um objeto, um número de leito ou de prontuário, uma síndrome ou um órgão doente. Frente à realidade da hospitalização e da doença, é inevitável a transformação do paciente em relação a seus hábitos, restando a ele, em muitas ocasiões, apenas assistir ao extermínio de seus direitos existenciais: o direito de ser, de existir enquanto pessoa.

A humanização surge como meio de diminuir 
o impacto dessa nova realidade para a pessoa, procurando tratar o doente, e não somente a doença. Dessa forma, podemos pensar que o psicólogo deve reconhecer que o paciente hospitalizado tem uma história, anseios e que a doença possui um lugar singular na vida de cada paciente, pois isso é o que permite ao sujeito se reconhecer como pessoa novamente, cindindo o processo de despersonalização. Para isso, consideramos que, além de reconhecer o paciente como uma pessoa com uma história, é preciso possibilitar que ele expresse o que está sentindo e elabore esses sentimentos. $\mathrm{O}$ projeto lúdico busca, através do brincar, resgatar essa individualidade que pode ser perdida na hospitalização e, assim, possibilita um tratamento mais humano ao paciente.

A doença é uma oportunidade de ressignificar a vida, de reconstruir, mas essa reconstrução não só está ligada ao próprio paciente mas também ao apoio que ele tem da família e dos amigos e da forma como será tratado pela equipe profissional. Esse é mais um motivo para o esforço atual dos hospitais no sentido de humanizar o tratamento.

Dessa forma, em um contexto tão singular como o hospital, (no qual estão presentes a dor, o sofrimento, a angústia e o medo), o psicólogo clínico deve que adequar suas técnicas para atender as demandas desse setting, focando o momento, pois nem sempre é possível obter um processo terapêutico com o paciente. Um projeto como o descrito possibilita, através do resgate do lúdico, a iniciação e a finalização do trabalho terapêutico com esses pacientes internados, contribuindo para sua qualidade de vida e para o enfrentamento da doença.

\section{Considerações finais}

Ao trabalhar de perto com questões acerca da morte, estamos envolvidos com a vida, que é trabalhada, mesmo que o assunto seja a morte. Pensamos em formas de investir na qualidade da existência da pessoa, seja qualidade de vida, seja de morte.

A Psicologia se faz presente, muitas vezes, sem ser solicitada pelo paciente, e se depara com diferentes percepções, estados físicos e emocionais. Às vezes, vem simplificar e clarear algo nebuloso ou desconhecido: tornar familiar o que é o câncer, a função dos tratamentos, ajudar o paciente a se tornar o "personagem principal", com autonomia, permitindo que aspectos pessoais e subjetivos (responsabilidade, participação, parceria com a equipe) sejam usados a seu favor, para lutar por sua qualidade de vida e/ou de morte. A Psicologia pode ajudar o paciente a perceber outros aspectos de sua vida, não só o adoecimento mas também os diversos elementos que envolvem os diferentes papéis que desempenha.

A presença da família, da equipe de saúde e do psicólogo são necessárias para o doente compartilhar a dor, amenizando a solidão do adoecimento. $\mathrm{E}$, no meio de tudo isso, e muito mais, a Psicologia se apresenta com cuidados que enfatizam a vida, o desejo, a individualidade, a individuação, não só no atendimento psicológico mas também nas atividades que focalizam esses aspectos, mesmo indiretamente: a participação em jogos, em produções artísticas e no envolvimento com o brincar. A Psicologia torna visível outro lado, pois não só há o adoecer, mas o ser cuidado, o criar, a possibilidade de cada paciente mostrarse, de expor algo de si em um ambiente em que, muitas vezes, se está à mercê de um cuidador; permite rir, contar aspectos bons de seu passado ou presente, expor preocupações e alegrias, compartilhar pensamentos, aspectos de seu viver com outros que passam por situações parecidas, ou muito diferentes, "escutar" outras vidas e 
propiciar maior proximidade com a equipe, quando esta participa.

Essas atividades que envolvem o ato de brincar contribuem até mesmo como instrumento para o trabalho terapêutico da Psicologia, tornando o profissional mais próximo do paciente e da equipe. Dessa forma, a Psicologia, com seus princípios e propostas, pode exercer a função de facilitadora da expressão de aspectos internos, íntimos, sentimentos, emoções, pensamentos e trocas.

Na experiência clínica específica abordada neste trabalho, entre uma das técnicas de atuação do psicólogo, está o projeto lúdico, com uma abordagem que pode ser tanto grupal como individual, e que consideramos inovadora por permitir essa flexibilidade, principalmente por ser um instrumento que utiliza o brincar na reorganização psíquica de pacientes adultos em tratamento de câncer.

A partir dos conteúdos internos que o brincar mobiliza, como forma de reorganizar e ressignificar, por meio do simbólico, os conflitos e as dores e trazer à tona (o além do adoecer) os aspectos revigorantes de vida que podem estar presentes mesmo no momento do adoecer, essa atividade pode levar o indivíduo a se tornar novamente o centro de sua existência. Sendo assim, podemos considerar que o brincar, independentemente do sujeito participante, pode ser um dos recursos para o indivíduo elaborar suas questões de vida e morte. 


\section{Renata Carolina Giuliano*}

Psicóloga, especialista em Psicologia Hospitalar pelo Serviço de Psicologia Hospitalar da Irmandade da Santa Casa de Misericórdia de São Paulo (ISCMSP), psicóloga do Serviço de Psicologia Hospitalar da ISCMSP, São Paulo, SP - Brasil.

\section{Luciana Marcia dos Santos Silva}

Psicóloga, especializanda em Psicologia Clínica: Psicoterapia Psicodinâmica (área de concentração: psicoterapia breve - adultos) pelo Instituto Paulista de Psicologia, Estudos Sociais e Pesquisa (IPPESP), São Paulo, SP - Brasil. E-mail: Ilucianamarcia@ig.com.br.

\section{Nataly Manhães Orozimbo}

Psicóloga, especializanda em Psicologia Clínica: Psicoterapia Psicodinâmica (área de concentração: psicoterapia breve - adultos) pelo Instituto Paulista de Psicologia, Estudos Sociais e Pesquisa (IPPESP), São Paulo, SP - Brasil. E-mail: natalymanhaes@hotmail.com

\section{*Endereço para envio de correspondência:}

Rua Frei Caneca, 342 - Consolação, São Paulo, SP - Brasil - CEP: 01307-000

E-mail: renata_giuliano@yahoo.com.br

Recebido 07/10/2008, Reformulado 27/04/2009, Aprovado 18/05/2009

Referências

Angerami-Camon, V. A. (2003). O Psicólogo no hospital. In V. A. Angerami-Camon (Org.), Psicologia hospitalar: teoria e prática (Cap. 1, pp. 15-28). São Paulo: Pioneira Thomson Learning.

Barbosa, L. N. F., \& Francisco, A. L. (2007, junho). A subjetividade do câncer na cultura: implicações na clínica contemporânea. Revista da SBPH, 10(1), 9-24.

Campos, T. C. P. (1995). Psicologia hospitalar: a atuação do psicólogo em hospitais. São Paulo: EPU.

Chiattone, H. B. C. (1992). Uma vida para o câncer. In V. A. Angerami-Camon (Org.), O doente, a psicologia e o hospital (Cap. 4, pp. 71-100). São Paulo: Pioneira.

Cunha, N. H. S. (1994). Brinquedoteca: um mergulho no brincar (2a ed., pp. 20-21). São Paulo: Maltese.

Ferraz, M. H. C. T., \& Fusari, M. F. R. (1999). Metodologia do ensino de arte (2a. ed.). São Paulo: Cortez.

Figueiredo, L. C. M. (2004). Revisitando as psicologias: da epistemologia à ética das práticas e discursos psicológicos (3a ed. rev. e ampl.). Petrópolis, RJ: Vozes.

Freud, S. (1976). Edição standard brasileira das obras psicológicas completas de Sigmund Freud. (Vol. 9). Rio de Janeiro: Imago.

Leão, N. (1994). O paciente terminal e a equipe interdisciplinar. In B. W. Romano (Org.), A prática da psicologia nos hospitais (Cap. 9, pp. 137-147). São Paulo: Pioneira.

Mrech, L. M. (1998). Além do sentido e do significado: a concepção psicanalítica da criança e do brincar (Cap. 8, pp. 155-172). In T. M. Kishimoto (Org.), O brincar e suas teorias. São Paulo: Pioneira.

Pedroza, R. L. S. (2005). Aprendizagem e subjetividade: uma construção a partir do brincar. Revista do Departamento de Psicologia - UFF, 17(2), 61-76.
Pitta, A. (1994). Hospital: dor e morte como ofício (3a ed.). São Paulo: Hucitec.

Rodulfo, R. (1990). O brincar e o significante: um estudo psicanalítico sobre a constituição precoce. Porto Alegre: Artes Médicas.

Romano, B. W. (2001). Psicologia e cardiologia: encontros possíveis. São Paulo: Casa do Psicólogo.

Santos, N. E. (2003). Quando o corpo se faz despertar. In J. Quayle \& M. C. S. Lucia (Orgs.), Adoecer: as intervenções do doente com sua doença (Cap. 1, pp. 3-8). São Paulo: Atheneu.

Simões, A. L. B. Ludoterapia: o brincar. Recuperado em 09 de setembro de 2006, de http://www.lifepsicologia.com.br/ lifepsicologia/artigos/ludoterapia.asp

Souza, C. B. (2003). Corpoalma com câncer. In J. Quayle \& M C. S. Lucia (Orgs.), Adoecer: as intervenções do doente com sua doença (Cap. 11, pp. 143-151). São Paulo: Atheneu.

Stephan, M. C. (2002). A vivência do tempo no paciente oncológico. In D. S. P. Castro, D. D. Pokladek, F. P. Ázar, J. D. Piccino, \& R. S. Josgrilberg (Orgs.), Existência e saúde (pp. 215-219). São Bernardo do Campo, SP: Umesp.

Vasconcellos, E. A., \& Giglio, J. S. (2007). Introdução da arte na psicoterapia: enfoque clínico e hospitalar. Estudos de Psicologia (Campinas), 24(3), 375-383.

Winnicott, D. W. (1971). O brincar e a realidade (J. O. de Aguiar \& V. Nobre, Trads.). Rio de Janeiro: Imago. Título original: Playing and reality. 